\title{
Spatial variation in bird pollination and its mitigating effects on the genetic diversity of pollen pools accepted by Camellia japonica trees within a population at a landscape level
}

\author{
Atsushi Nakanishi ${ }^{1} \cdot$ Tomoe Takeuchi $^{2,5} \cdot$ Saneyoshi Ueno ${ }^{3} \cdot$ Naoyuki Nishimura $^{4} \cdot$ Nobuhiro Tomaru $\mathbb{D}^{2}$
}

Received: 30 March 2019 / Revised: 10 August 2019 / Accepted: 12 August 2019 / Published online: 4 September 2019

(c) The Author(s), under exclusive licence to The Genetics Society 2019

\begin{abstract}
Bird pollination can vary spatially in response to spatial fluctuations in flowering even within plant populations. In this study, we examined the hypothesis that the spatial variation in bird pollination may induce mitigating effects, which maintains or increases genetic diversity of pollen pools at local sites with low flowering densities. To test this hypothesis, we analyzed the landscape-level genetic effects within a population of Camellia japonica on the pollen pools accepted by individuals in two reproductive years by using genotypes at eight microsatellite loci of 1323 seeds from 19 seed parents. Regression analyses using the quadratic models of correlated paternity between pollen pools against spatial distances between the seed-parent pairs revealed not only local pollination but also some amount of long-distance pollen dispersal. The genetic diversity of pollen pools accepted by seed parents tended to be negatively related to the densities of flowering individuals near the seed parents during winter (when the effective pollination of $C$. japonica is mediated mostly by Zosterops japonica). We show that the low density of flowering individuals may induce the expansion of the foraging areas of $Z$. japonica and consequently increase the genetic diversity of pollen pools. This spatial variation in bird pollination may induce the mitigating effects on the $C$. japonica population. The comparisons between the two study years indicate that the overall pattern of bird pollination and the genetic effects described here, including the mitigating effects, may be stable over time.
\end{abstract}

Supplementary information The online version of this article (https:// doi.org/10.1038/s41437-019-0262-7) contains supplementary material, which is available to authorized users.

Nobuhiro Tomaru

tomaru@agr.nagoya-u.ac.jp

1 Hokkaido Research Center, Forestry and Forest Products Research Institute, Forest Research and Management Organization, 7 Hitsujigaoka, Toyohira-ku, Sapporo 062-8516, Japan

2 Graduate School of Bioagricultural Sciences, Nagoya University, Furo-cho, Chikusa-ku, Nagoya 464-8601, Japan

3 Department of Forest Molecular Genetics and Biotechnology, Forestry and Forest Products Research Institute, Forest Research and Management Organization, 1 Matsunosato, Tsukuba, Ibaraki 305-8687, Japan

4 Faculty of Social and Information Studies, Gunma University, 4-2 Aramaki-machi, Maebashi, Gunma 371-8510, Japan

5 Present address: Forestry Department, Saku Regional Development Bureau, Nagano Prefectural Government, 65-1 Atobe, Saku, Nagano 385-0054, Japan

\section{Introduction}

Local flowering density (defined in this study as the number of flowers produced per flowering individual and the density of flowering individuals at a site) may affect the patterns of animal pollination. Considering that optimally foraging pollinators are expected to minimize energetic costs during foraging bouts by moving preferentially between nearby flowers (Krauss et al. 2017), high flowering densities per individual would induce short-distance pollination. Furthermore, high densities of flowering individuals may induce animal pollinators to forage more locally, thereby reducing pollen dispersal distances (Hardy 2009). On the contrary, low flowering densities should increase the distances of animal pollination. Therefore, the distance might negatively depend on the flowering density. In this study, we describe such relationship as "negative densitydependence of pollination distance". According to the model $N_{\mathrm{ep}}=8 \delta^{2} d$ (Austerlitz and Smouse 2001), where $N_{\mathrm{ep}}$, $\delta$, and $d$ are the effective number of pollen parents, mean distance of pollen dispersal, and density of reproductive 
individuals, respectively, $N_{\mathrm{ep}}$ theoretically decrease with decreasing $d$ if $\delta$ is assumed to be constant (Austerlitz and Smouse 2001). However, the negative density-dependence of pollination distance, which increases $\delta$ as $d$ decreases as observed in some animal-pollination in forest tree species (Stacy et al. 1996; White et al. 2002; Fukue et al. 2007), could mitigate the effect of decreasing $d$, thus maintaining or increasing both $N_{\mathrm{ep}}$ and the consequent genetic diversity of pollen pools (mitigation effect). Therefore, if flowering density spatially vary within a population, pollen dispersal patterns may vary among seed parents that accept pollen depending on local flowering density even within continuous populations at the landscape level. Owing to the spatial variation in pollen dispersal, the genetic diversity of pollen pools accepted by each seed parent might also spatially vary even within populations. The consequent mitigation effect on the genetic diversity of pollen pools could contribute to the preservation of genetic diversity within populations by maintaining or increasing the genetic diversity of offspring from seed parents at local sites with low flowering density. However, such spatial variations in pollen dispersal and the consequent genetic diversity of pollen pools within continuous populations have not been fully elucidated.

The effects of flowering density on pollination depend on the pollination vectors (Breed et al. 2015a). Although the reduced density of small-insect-pollinated species may led to provision of low pollen diversity, the bird-pollinated forest tree species may not suffer from the effects of decreased density owing to the ability to sample larger and more diverse pollination neighborhoods (Breed et al. 2015a). Such mitigation effect probably due to the negative density-dependence of bird-pollination has been indicated by previous studies on forest tree species (Abe et al. 2011; Breed et al. 2015a, 2015b). Bird pollination can be characterized by high mobility and high energy needs, which may induce birds to visit several widely scattered nectar sources (Stiles 1978). Owing to the negative densitydependence of pollination distance based on the ability of birds to track fluctuations in flowering better than insects (Stiles 1978), low flowering density should substantially promote pollen dispersal via birds. Therefore, birdpollination patterns may vary spatially in response to the spatial fluctuations of flowering even within a population.

Although the optimal foraging behavior of nectar- or pollen-feeding animals has been thought to result in shortdistance pollen dispersal, as well as frequent selfing, biparental inbreeding, and highly correlated paternity within maternal sibships (Bezemer et al. 2016; Krauss et al. 2017), Krauss et al. (2017) predicted that high mobility, limited grooming, and aggression are likely to be key behavioral characteristics of birds that facilitate pollen carryover and promote high mate diversity in plant species. Therefore, these behavioral characteristics, as well as the effect of flowering density, should be examined to elucidate the genetic effect of bird pollination. Furthermore, an examination on the stability of pollination patterns across different reproductive years is essential for the exact characterization of the pollination pattern.

Camellia japonica blossoms in winter when pollinators other than birds are usually scarce because the low temperatures restrict the activities of insect pollinators (Fang et al. 2012). C. japonica strongly depends on the bird species Zosterops japonica (Japanese white-eye) for pollination and the bird strongly depends on $C$. japonica for food resources in winter (Kunitake et al. 2004). Furthermore, the flowering density of the species may vary spatially even within a population at a landscape level. Therefore, an examination of the relationship between flowering density during winter and genetic diversity of pollen pools in such populations of $C$. japonica could reveal the effect of flowering density on bird pollination. Previous studies on $C$. japonica populations have shown that the high mobility and effectiveness of Zosterops japonica as a pollinator may strongly contribute to the maintenance of pollen genetic diversity (Abe et al. 2011, 2013). However, these studies have only been conducted at small scales (0.3-1.0 ha plots), and spatial variation in pollination and its consequent genetic effects on pollen pools within a population have yet to be examined.

In this study, we examined the overall patterns of bird pollination in Camellia japonica and their stability across different reproductive years within an intact and continuous forest at a landscape scale. We also examined the hypothesis that the spatial variation in bird pollination, in response to the spatial fluctuations of flowering, may induce mitigating effects, which maintains or increases genetic diversity of pollen pools at local sites with low flowering densities within a population.

\section{Materials and methods}

\section{Study site}

The study site was in the Tatera Forest Reserve $\left(34^{\circ} 9^{\prime} \mathrm{N}\right.$, $129^{\circ} 13^{\prime} \mathrm{E}$ ) on the South Island of Tsushima, which belongs to Nagasaki Prefecture in Japan and is located between the Japanese Archipelago and Korean Peninsula. The reserve is protected as a national natural monument, covers $\sim 100$ ha, and is situated on the north-facing slope of Mt. Tatera ( $560 \mathrm{~m}$ above sea level). There has been no human interference in the reserve for several centuries, and an oldgrowth, evergreen, broad-leaved forest is well developed (Itow 1991). The vegetation features of the forest have been described by Manabe et al. (2000), who investigated all tree stems with a diameter at breast height $(\mathrm{DBH}) \geq 5 \mathrm{~cm}$ in a 
Fig. 1 Locations of the 19 seed parents (circles with ID numbers) of Camellia japonica

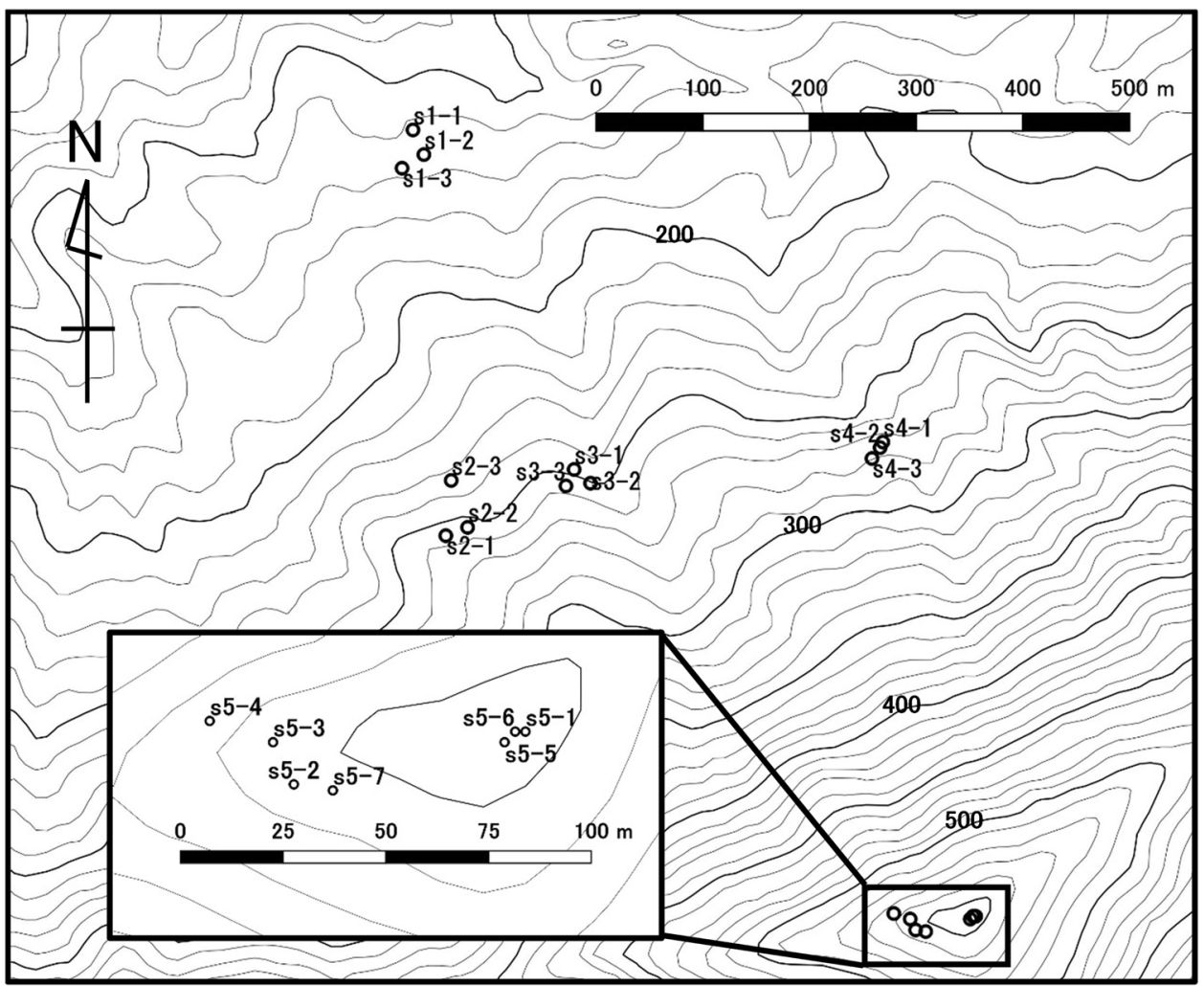

4 ha plot established within the forest. The plot contained a total of 45 species and 4570 living stems $\geq 5 \mathrm{~cm} \mathrm{DBH}$, with a total basal area of $63.9 \mathrm{~m}^{2} \mathrm{ha}^{-1}$. The dominant species in terms of stem density was Distylium racemosum (Hamamelidaceae) at 410.0 stems ha $^{-1}$, but Castanopsis sieboldii (Fagaceae) was dominant in terms of basal area at $24.9 \mathrm{~m}^{2} \mathrm{ha}^{-1}$. Camellia japonica was only one birdpollinated species in the major species in the plot and had the fifth largest basal area $\left(2.4 \mathrm{~m}^{2} \mathrm{ha}^{-1}\right)$ and third-highest density (143.3 stems ha ${ }^{-1}$ ).

\section{Study species}

Camellia japonica, which is an evergreen broad-leaved tree of the family Theaceae, is distributed throughout Japan, Korea, and China. The species commonly dominates the subcanopy layer in warm-temperate, evergreen, broadleaved forests in Japan. It produces hermaphrodite flowers from November to April (Kunitake et al. 2004). Its pollen is mainly dispersed by Japanese white-eye birds (Zosterops japonica; Kunitake et al. 2004), and its seeds are dispersed primarily by gravity and secondarily (in some places) by mice (Abe et al. 2006). This species is self-incompatible (Wendel and Parks 1984), and its flowers do not set fruits without pollinator visitation (Kunitake et al. 2004). Kunitake et al. (2004) found that fruit set in flowers visited by birds was sixfold greater than that in flowers without bird visitation and the level of fruit set was saturated by only five visitations of $Z$. japonica. Furthermore, most visitors to the flowers were $Z$. japonica individuals in the field observation (Kunitake et al. 2004). Therefore, pollination by Z. japonica should be important for the seed production and the contribution by pollinators other than $Z$. japonica may be minor.

\section{Field methods}

In September 2006, we sampled leaves and seeds from 16 Camellia japonica seed parents: 3 seed parents at each of 4 sites (s1, s2, s3, and s4) and 4 seed parents at another site (s5) in the 100 ha old-growth, evergreen, broad-leaved forest (Fig. 1, Table 1). In September 2008, we sampled seeds from 16 seed parents: 13 seed parents that were also in the previous set ( 1 seed parent at s5 and 3 seed parents each at s1, s2, s3, and s4) and other 3 seed parents at s5. In addition to seeds, leaves were collected from the three seed parents at s5. In total, we sampled leaves and 1323 seeds from 19 seed parents. The number of fruits sampled from each seed parent ranged from 4 to 11 , and the number of seeds sampled from each fruit ranged from 1 to 13 .

The locations of all seed parents were determined by hand-held GPS units (eTrex Vista C or Colorado 300, Garmin, Kansas, USA). The mean distances between pairs of the 16 seed parents sampled in 2006, 16 seed parents 
Table 1 Numbers of analyzed seeds from 19 seed parents in the two reproductive years

\begin{tabular}{|c|c|c|c|}
\hline Site & Seed parent & $N_{2006}$ & $N_{2008}$ \\
\hline \multirow[t]{3}{*}{ s1 } & s1-1 & 26 & 58 \\
\hline & $\mathrm{s} 1-2$ & 35 & 78 \\
\hline & s1-3 & 28 & 57 \\
\hline \multirow[t]{3}{*}{ s2 } & s2-1 & 17 & 53 \\
\hline & s2-2 & 20 & 40 \\
\hline & s2-3 & 29 & 59 \\
\hline \multirow[t]{3}{*}{ s3 } & s3-1 & 28 & 59 \\
\hline & s3-2 & 25 & 66 \\
\hline & s3-3 & 19 & 37 \\
\hline \multirow[t]{3}{*}{ s4 } & s4-1 & 31 & 54 \\
\hline & s4-2 & 29 & 70 \\
\hline & s4-3 & 28 & 57 \\
\hline \multirow[t]{7}{*}{ s5 } & s5-1 & 21 & \\
\hline & s5-2 & 33 & 40 \\
\hline & s5-3 & 35 & \\
\hline & s5-4 & 25 & \\
\hline & s5-5 & & 51 \\
\hline & s5-6 & & 67 \\
\hline & s5-7 & & 48 \\
\hline Total & & 429 & 894 \\
\hline
\end{tabular}

$N_{2006}$ and $N_{2008}$ indicate the numbers of analyzed seeds in the reproductive years of 2006 and 2008, respectively

sampled in 2008, and 13 seed parents sampled in both years were $442.9 \pm 270.8$ (standard deviation), $448.1 \pm 276.6$, and $362.1 \pm 227.4 \mathrm{~m}$, respectively, and those within sites were $33.3 \pm 20.6,31.1 \pm 18.4$, and $28.8 \pm 16.4 \mathrm{~m}$, respectively.

To quantify the density of flowering individuals at each site over the entire flowering period and particularly during winter, we monitored the flowering of 14 of the 16 seed parents sampled in 2006 (s1-1, s1-2, s1-3, s2-1, s2-2, s2-3, s3-1, s3-2, s3-3, s4-1, s4-2, s4-3, s5-1, and s5-2; see Table 1) and all other Camellia japonica individuals within $10 \mathrm{~m}$ radii from the respective seed parents. In surveys lasting one to 3 days, we recorded the flowering status (flowering or nonflowering) for each of these individuals nine times from November 2007 to June 2008 (except for seed parent s2-2, which was not surveyed on the first occasion). Furthermore, to estimate the flowering amplitude of each of these individuals at each site over the entire flowering period, we counted fallen flowers under its crown at each survey, removed them from the site, and summed the numbers of flowers that had fallen from each individual recorded in all surveys. If a fallen flower was located under overlapping crowns of multiple $C$. japonica individuals, we allocated the flower to one of the individuals, the stem of which was nearest to the flower.

\section{DNA extraction and microsatellite genotyping}

Genomic DNA was extracted from sampled leaves and seeds by using the hexadecyltrimethylammonium bromide method (Murray and Thompson 1980) with minor modifications. Eight expressed sequence tag microsatellite loci, namely, MSE0030, MSE0045, MSE0049, MSE0051, MSE0062, MSE0078, MSE0079, and MSE0087, which were originally developed for Camellia sinensis (Taniguchi et al. 2012) were selected for genotyping adults and seeds. Genotyping at the microsatellite loci was performed by capillary electrophoresis using a 3100 Genetic Analyzer and GeneScan software (Applied Biosystems, California, USA).

\section{Estimation of polymorphism at microsatellite loci}

Polymorphisms at the eight microsatellite loci were characterized by calculating the following standard population genetic parameters on the basis of the genotypes of all 19 sampled seed parents: observed number of alleles $\left(N_{\mathrm{O}}\right)$, effective number of alleles $\left(N_{\mathrm{E}}\right)$, observed heterozygosity $\left(H_{\mathrm{O}}\right)$, and gene diversity $\left(H_{\mathrm{E}}\right)$ for each locus and all eight loci.

\section{Analysis of mating systems}

We estimated mating systems by using MLTR software version 3.4 (Ritland 2002) as follows. We calculated singleand multilocus estimates of outcrossing rates $\left(t_{\mathrm{s}}\right.$ and $t_{\mathrm{m}}$, respectively) and estimated the level of biparental inbreeding from the difference between multilocus and mean single-locus rates $\left(t_{\mathrm{m}}-t_{\mathrm{s}}\right)$. We also calculated the multilocus estimates of the correlation of paternity $\left(r_{\mathrm{p}}\right)$, which is the probability that two maternal sibs are outcrossed full-sibs sharing the same pollen parent and is the inverse of the effective number of pollen parents $\left(N_{\mathrm{ep}}\right.$; Smouse and Robledo-Arnuncio 2005). The above parameters were calculated separately for each of the two reproductive years covered in the study by using the Newton-Raphson method incorporated in the software constraining allele frequencies of pollen to equal to those of ovule (default settings) on the basis of the genotypes of seeds and seed parents. Their standard deviations were estimated by bootstrap resampling 1000 times, and all 16 seed parents sampled in each year were included in these analyses.

\section{Analysis of correlated paternity of pollen pools between seed-parent pairs and the overall patterns of pollen dispersal}

Correlated paternity, i.e., the probability of offspring sired by the same paternal parent in different maternal families, can be used to investigate biological factors determining 
effective pollination (Hardy et al. 2004; Oddou-Muratorio et al. 2006) and has been expressed as a function of pollen dispersal distribution (Austerlitz and Smouse 2001; Robledo-Arnuncio et al. 2006). To examine the overall pollen dispersal pattern within a population of Camellia japonica in an indirect manner, the spatial pattern of correlated paternity was analyzed as follows.

First, the correlated paternity of pollen pools was estimated between all seed-parent pairs in each of the two reproductive years from the obtained genotypes of seed parents and seeds by using the POLDISP software package (Robledo-Arnuncio et al. 2007). Then, to examine the similarity of pollen dispersal patterns between the two years, we calculated the Spearman's rank correlation coefficient between the years for the correlated paternity values of pollen pools accepted by each seed-parent pair for the 13 seed parents sampled in both years by using $\mathrm{R}$ ver. 3.3.3 ( $\mathrm{R}$ Development Core Team 2012). Furthermore, we used quadratic models to examine the regressions of the correlated paternity of pollen pools between seed-parent pairs against the spatial distances between the seed-parent pairs as follows:

$C_{\mathrm{p}}=a+b D+c D^{2}$,

where $C_{\mathrm{p}}$ is the correlated paternity, $D$ is the spatial distance between seed-parent pairs, $a$ is the parameter for intercept, $b$ is the parameter for coefficient in linear term, and $c$ is the parameter for coefficient in quadratic term. We examined the quadratic terms to assess whether the correlated paternity monotonically decreased as the distance between seedparent pairs increased and whether the correlated paternity reached a global minimum value at intermediate distances. This analysis was conducted for each of the two reproductive years, including all 16 seed parents sampled in each year by using R ver. 3.3.3 (R Development Core Team 2012).

We used the KINDIST model (Robledo-Arnuncio et al. 2006) implemented in the POLDISP software package to infer the pollen dispersal kernel (the probability density that pollen lands at a given position away from a source individual), on the basis of the exponential power function, for each of the two reproductive years (Supplementary Method S1 for more detail).

\section{Two-generation analysis}

Two-generation (two-gener) analysis (Smouse et al. 2001) can quantify the spatial genetic differentiation $\left(\Phi_{\mathrm{FT}}\right)$ among the pollen pools sampled by seed parents via the analysis of molecular variance (Excoffier et al. 1992) of pollen haplotypes. Modified versions of the analysis (Irwin et al. 2003) can also quantify interannual genetic differentiation among the pollen pools sampled by each seed parent $\left(\Phi_{\mathrm{YF}}\right)$ and global pollen pools averaged for all seed parents $\left(\Phi_{\mathrm{YG}}\right)$. $\Phi_{\mathrm{FT}}$, which is analogous to Wright's $F_{\mathrm{ST}}$ value and an inverse function of mean pollination distance (Smouse et al. 2001), reflects landscape-level gene movement via pollen. $\Phi_{\mathrm{YF}}$ and $\Phi_{\mathrm{YG}}$ reflect the interannual variation in the contributions of pollen donors to the pollen pools accepted by each seed parent and all seed parents, respectively. To examine patterns of pollen dispersal for each year and the interannual variation of pollination at a landscape level within a population, we conducted two-gener analyses on the basis of the genotypes of seeds and seed parents by using the three methods described in Supplementary Method 2. The GENEALEX 6.3 software package (Peakall and Smouse 2006) was used for all two-gener analyses to estimate the $\Phi$ statistics. We also used $\Phi_{\text {FT }}$ values to calculate the effective number of pollen parents $\left(N_{\mathrm{ep}}\right.$; Smouse et al. 2001) from the equation $N_{\mathrm{ep}}=1 / 2 \Phi_{\mathrm{FT}}$.

\section{Analysis of the genetic diversity of pollen pools}

To test a hypothesis about the mitigating effects of bird pollination within a population, we examined the effect of the local density of flowering individuals on the genetic diversity of pollen pools accepted by seed parents as follows. Considering that Camellia japonica strongly depends on effective pollination by Zosterops japonica and that birds strongly depend on $C$. japonica for food resources during winter (Kunitake et al. 2004), flowering density during winter should strongly affect pollination dynamics. Thus, we used the density of flowering individuals only during winter (from December 20-21, 2007 to February $22-23,2008)$ in the following analyses.

First, we estimated genetic diversity of pollen pools as follows. The paternal alleles of each seed were identified by subtracting the maternal alleles from the seed genotype (see Supplementary Method 3). By using the frequencies of paternal alleles in pollen pools, we calculated the gene diversity $\left(H_{\mathrm{E}}\right)$ of accepted pollen pools for each seed parent in each of the two reproductive years.

Second, to examine whether the levels of genetic diversity of pollen pools accepted by each seed parent tended to be consistent between the two years, we examined Spearman's rank correlation coefficient between the two years for the $H_{\mathrm{E}}$ values of pollen pools accepted by each seed parent. This analysis was conducted for the 13 seed parents sampled in both years using R ver. 3.3.3 (R Development Core Team 2012).

Third, we used linear regression to analyze the effect of density of flowering individuals near respective seed parents on the genetic diversity of pollen pools accepted by seed parents. The response variable was pollen pool $H_{\mathrm{E}}$ value (estimated from seeds sampled in 2008), and the explanatory variable was the density of individuals flowering during winter (from December 20-21, 2007 to February 22-23, 2008) within a $10 \mathrm{~m}$ radius of the seed parent. Given that the densities of flowering individuals within $10 \mathrm{~m}$ of s5-5, 
s5-6, and s5-7 were not observed, we used the values for s5$1, \mathrm{~s} 5-1$, and $\mathrm{s} 5-2$ as proxies because these were relatively close to s5-5 $(6.0 \mathrm{~m})$, s5-6 $(2.6 \mathrm{~m})$, and $\mathrm{s} 5-7(9.7 \mathrm{~m})$, respectively. $\mathrm{R}$ ver. 3.3.3 (R Development Core Team 2012) was also used for this analysis.

\section{Results}

\section{Flowering of seed parents and neighboring individuals}

In the surveys of flowering, we found 109 flowering Camellia japonica individuals in total at the five sites (including the 14 seed parents and other 95 individuals within the $10 \mathrm{~m}$ radii from the seed parents), which had at least one flower either on or under their crowns. The total flowering period of the 109 individuals lasted more than 6 months (Supplementary Fig. S1). The total number of flowers that fell from each tree over the entire flowering period varied among individuals within the $\mathrm{s} 1, \mathrm{~s} 2, \mathrm{~s} 3$, and $\mathrm{s} 4$ sites (mean \pm standard deviation; $199.6 \pm 254.1,157.8 \pm 249.7,280.2 \pm 493.8$, and $349.1 \pm 284.4$, respectively; Supplementary Fig. S2). At $\mathrm{s} 5$, it remained consistently low $(26.1 \pm 36.8)$. The densities of flowering individuals over the entire period were as follows: s1, $308 \mathrm{ha}^{-1}$; s2, $127 \mathrm{ha}^{-1}$; s3, $149 \mathrm{ha}^{-1}$; s4, $212 \mathrm{ha}^{-1}$; and $\mathrm{s} 5,684 \mathrm{ha}^{-1}$. Although the density of flowering individuals over the entire period was highest at the highest altitude site, namely, s5, the density during winter (when pollination of Camellia japonica may be mediated mostly by Zosterops japonica) tended to be higher at lower altitude sites (Table 2). Our linear regression analysis revealed that altitudes have a significantly negative effect on the density of flowering individuals during winter $(t=-2.710, P<0.05)$. At the lowest altitude site, namely, $\mathrm{s} 1$, the local density of flowering individuals during winter was highest $\left(202 \mathrm{ha}^{-1}\right)$. By contrast, at the highest altitude site, namely, s5, the density during winter was lowest $\left(48 \mathrm{ha}^{-1}\right)$.

\section{Polymorphism at the eight microsatellite loci}

The eight loci were highly polymorphic in the 19 sampled seed parents (Supplementary Table S1). In total, 64 alleles

Table 2 Mean altitude and mean density of Camellia japonica individuals flowering during winter at the five sites

\begin{tabular}{lll}
\hline Site & Mean altitude $(\mathrm{m})$ & Mean density during winter $\left(\mathrm{ha}^{-1}\right)$ \\
\hline s1 & 162 & 202 \\
s2 & 241 & 64 \\
s3 & 248 & 85 \\
s4 & 266 & 170 \\
s5 & 541 & 48 \\
\hline
\end{tabular}

Table 3 Mating system parameters in the two reproductive years

\begin{tabular}{lll}
\hline Mating system parameter & \multicolumn{2}{l}{ Reproductive year } \\
\cline { 2 - 3 } & 2006 & 2008 \\
\hline$t_{\mathrm{s}}$ & $0.894(0.024)$ & $0.921(0.017)$ \\
$t_{\mathrm{m}}$ & $0.966(0.017)$ & $0.985(0.008)$ \\
$t_{\mathrm{m}}-t_{\mathrm{s}}$ & $0.072(0.025)$ & $0.063(0.015)$ \\
$r_{\mathrm{p}}$ & $0.193(0.039)$ & $0.108(0.023)$ \\
$N_{\text {ep }}$ & 5.2 & 9.3 \\
\hline
\end{tabular}

Standard deviations estimated by 1000 times bootstrap resampling are in parentheses

$t_{\mathrm{s}}$ single-locus outcrossing rate, $t_{\mathrm{m}}$ multilocus outcrossing rate, $t_{\mathrm{m}}-t_{\mathrm{S}}$ level of biparental inbreeding, $r_{\mathrm{p}}$ multilocus correlation of paternity, $N_{\text {ep }}$ effective number of pollen parents $\left(1 / r_{\mathrm{p}}\right)$

were detected at the eight loci (three to 16 alleles per locus, with a mean of 8.0). The effective number of alleles $\left(N_{\mathrm{E}}\right)$ per locus ranged from 2.0 to 11.1 with a mean of 5.1. The observed heterozygosity $\left(H_{\mathrm{O}}\right)$ per locus ranged from 0.368 to 0.895 with a mean of 0.750 and gene diversity $\left(H_{\mathrm{E}}\right)$ per locus ranged from 0.511 to 0.935 with a mean of 0.763 .

\section{Mating systems}

The estimated multilocus outcrossing rates $\left(t_{\mathrm{m}}\right)$ in 2006 and 2008 were $0.966 \pm 0.017$ (standard deviation) and $0.985 \pm$ 0.008 , respectively (Table 3 ), and the estimated levels of biparental inbreeding $\left(t_{\mathrm{m}}-t_{\mathrm{s}}\right)$ in 2006 and 2008 were $0.072 \pm$ 0.025 and $0.063 \pm 0.015$, respectively. The estimated multilocus correlation of paternity within maternal sibs $\left(r_{\mathrm{p}}\right)$ was $0.193 \pm 0.039$ in 2006 and $0.108 \pm 0.023$ in 2008 . The estimated effective number of pollen parents (calculated as the inverse of $r_{\mathrm{p}}$ ) was 5.2 in 2006 and 9.3 in 2008.

\section{Correlated paternity of pollen pools between seed- parent pairs and the overall patterns of pollen dispersal}

The correlated paternity of pollen pools between the seedparent pairs examined ranged from -0.168 to 0.136 (mean \pm standard deviation, $-0.011 \pm 0.052$ ) and from -0.101 to $0.122(-0.007 \pm 0.035)$ in 2006 and 2008 , respectively. A significantly positive Spearman's rank correlation coefficient existed between the two reproductive years for the correlated paternity values of pollen pools accepted by each seed-parent pair $(r=0.602, P<0.001$, Fig. 2$)$.

Polynomial regressions using quadratic models significantly explained the relationships between the correlated paternity of pollen pools and spatial distance for seed-parent pairs in both years (2006: $F=30.9, P<0.001 ; 2008: F=$ 35.7, $P<0.001$; Fig. 3). For both years, both linear (2006: $t$ $=-7.469, P<0.001 ; 2008: t=-7.370, P<0.001)$ and quadratic terms (2006: $t=6.174, P<0.001 ; 2008: t=5.514$, 


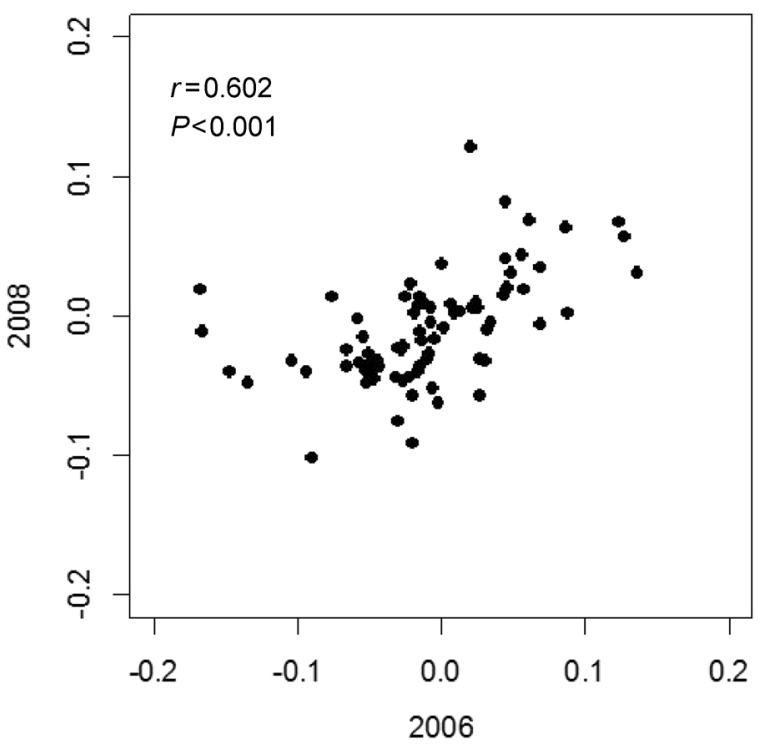

Fig. 2 Relationship between the reproductive years 2006 and 2008 of correlated paternity values of pollen pools accepted by each seedparent pair

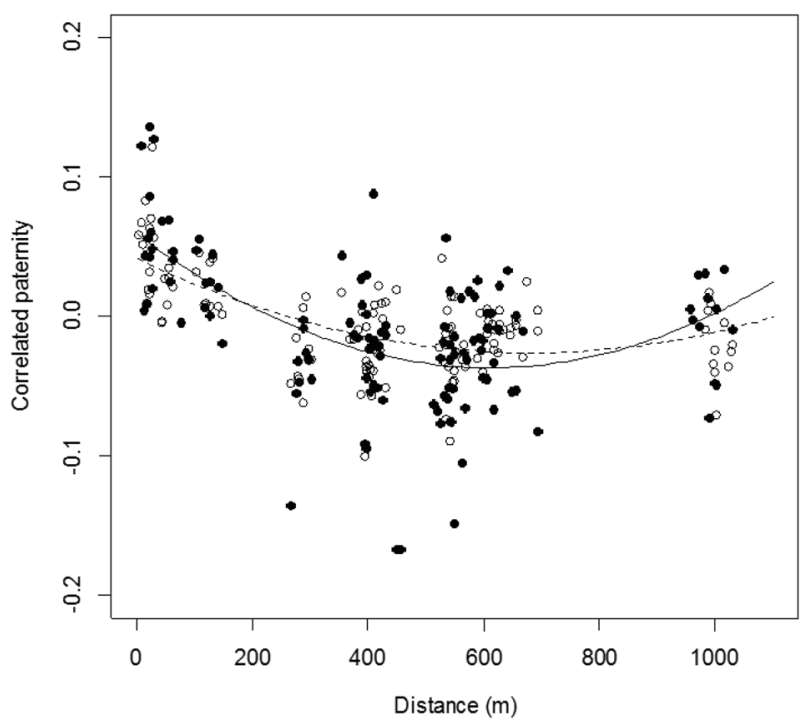

Fig. 3 Distributions of the correlated paternity between pollen pools as functions of the spatial distances between seed-parent pairs in 2006 (filled circles) and 2008 (open circles). The quadratic functions of the distance were fitted to the data. Solid and dashed curves indicate the functions for the reproductive years 2006 and 2008, respectively

$P<0.001$ ) were significant (Table 4). The significance of quadratic terms indicated that the expected correlated paternity did not monotonically decrease in the long ranges as the distance between seed-parent pairs increased, reaching global minimum values of -0.037 at a distance of $610.2 \mathrm{~m}$ in 2006 and -0.026 at $681.8 \mathrm{~m}$ in 2008 . Therefore, the correlated paternity decreased monotonically to the minimum values as the distances between seed-parent pairs
Table 4 Parameters estimated by quadratic models to examine the regressions of the correlated paternity of pollen pools between seedparent pairs against the spatial distances between the seed-parent pairs in the two reproductive years

\begin{tabular}{llll}
\hline Parameters & Estimate & Stndard error & $t$ statistic \\
\hline \multicolumn{2}{l}{ Reproductive } & & \\
$a$ & $5.917 \mathrm{E}^{-2}$ & $9.805 \mathrm{E}^{-3}$ & $6.035^{* * *}$ \\
$b$ & $-3.150 \mathrm{E}^{-4}$ & $4.217 \mathrm{E}^{-5}$ & $-7.469^{* * *}$ \\
$c$ & $2.581 \mathrm{E}^{-7}$ & $4.181 \mathrm{E}^{-8}$ & $6.174^{* * * *}$ \\
Reproductive year 2008 & & \\
$a$ & $4.162 \mathrm{E}^{-2}$ & $6.322 \mathrm{E}^{-3}$ & $6.584^{* * *}$ \\
$b$ & $-1.988 \mathrm{E}^{-4}$ & $2.698 \mathrm{E}^{-5}$ & $-7.370^{* * *}$ \\
$c$ & $1.458 \mathrm{E}^{-7}$ & $2.643 \mathrm{E}^{-8}$ & $5.514^{* * *}$ \\
\hline
\end{tabular}

Equation of the model: $C_{\mathrm{p}}=a+b D+c D^{2}$, where $C_{\mathrm{p}}$ is correlated paternity and $D$ is spatial distance between seed-parent pairs. $\mathrm{E}^{\mathrm{x}}$ means $10^{\mathrm{x}}$

${ }^{* * * *} P<0.001$

increased within the ranges of 0 to $610.2 \mathrm{~m}$ in 2006 and 0 to $681.8 \mathrm{~m}$ in 2008 but increased beyond those ranges.

The Spearman's rank correlation coefficients between the correlated paternity and distance between seed-parent pairs were -0.360 in $2006(P<0.001)$ and -0.392 in $2008(P<$ $0.001)$. According to the KINDIST model, by assuming an exponential power function as the dispersal kernel, the estimated scale parameter $(a)$, shape parameter $(b)$, and average pollination distance $(\delta)$ in 2006 were 0.000036 , 0.156 , and $1487.4 \mathrm{~m}$, respectively (model least-squared residual: 5.249; Fig. 4). The estimates of $a, b$, and $\delta$ in 2008 were $0.000190,0.168$, and $1476.9 \mathrm{~m}$ (model least-squared residual: 4.556), respectively. The dispersal kernels in the 2 years were very similar (Fig. 4).

\section{Genetic differentiation of pollen pools among seed parents and between years}

Two-gener analysis based on model 1 (see Supplementary Method S2) revealed the significant but low genetic differentiation of accepted pollen pools among seed parents in both years $\left(\Phi_{\mathrm{FT}}=0.105\right.$ and 0.070 , respectively; $P<$ 0.005). The analysis based on model 2 revealed the significant but low genetic differentiation of accepted pollen pools among seed parents $\left(\Phi_{\mathrm{FT}}=0.061, P<0.005\right)$ and between the two years nested within seed parents $\left(\Phi_{\mathrm{YF}}=\right.$ $0.029, P<0.005)$. The analysis based on model 3 showed no significant genetic differentiation of the global pollen pool averaged for all seed parents between the 2 years (global $\Phi_{\mathrm{YG}}=-0.003$ ). However, it indicated significant but low genetic differentiation among seed parents nested within years $\left(\Phi_{\mathrm{FT}}=0.087, P<0.005\right)$. The effective number of pollen parents $\left(N_{\mathrm{ep}}\right)$ based on model 1 was 4.8 for 


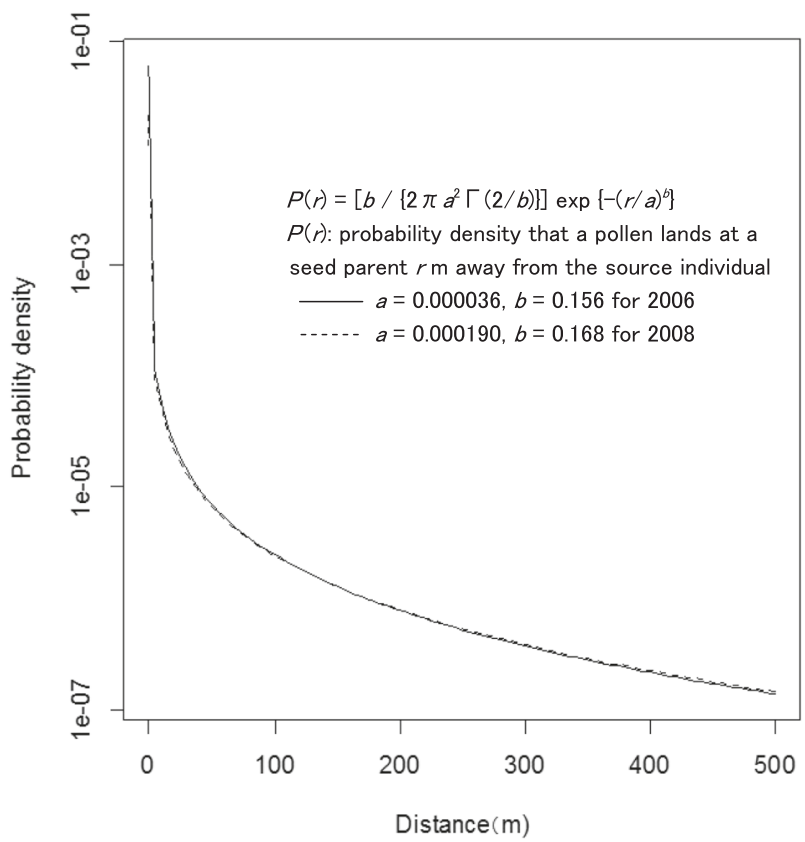

Fig. 4 Pollen dispersal kernels estimated by KINDIST model assuming the exponential power functions for reproductive years 2006 and 2008. The vertical axis indicates the probability density $P(r)$ that a pollen lands at a seed parent $r \mathrm{~m}$ away from the source individual (a value of $\mathrm{e}^{-\mathrm{x}}$ in the scale indicates $10^{-\mathrm{x}}$, in the display style of $\mathrm{R}$ program). The abscissa axis indicates the distance $r$. Solid and dashed curves indicate the kernels for the reproductive years 2006 and 2008, respectively

2006 and 7.1 for 2008 (estimated from $\Phi_{\mathrm{FT}}$ values), whereas the $N_{\text {ep }}$ value based on model 2 was 8.2.

\section{Genetic diversity of pollen pools}

The $H_{\mathrm{E}}$ values of pollen pools accepted by each seed parent ranged from 0.450 to 0.736 in 2006 (mean \pm standard deviation, $0.658 \pm 0.069)$ and from 0.593 to 0.760 in $2008(0.697 \pm$ 0.049). A significantly positive Spearman's rank correlation coefficient existed between the two reproductive years of the $H_{\mathrm{E}}$ values of pollen pools accepted by each seed parent $(r=$ $0.683, P<0.05$; Supplementary Fig. S3). The $H_{\mathrm{E}}$ values of pollen pools tended to be negatively related to the density of flowering individuals near respective seed parents during winter (Fig. 5; linear regression analysis, $F=4.8, P<0.05$ ).

\section{Discussion}

\section{Overall patterns of Camellia japonica gene dispersal via bird pollination}

Despite the high density of Camellia japonica reproductive individuals in our study, our estimates of multilocus selfing rate $\left(1-t_{\mathrm{m}}\right)$, biparental inbreeding level $\left(t_{\mathrm{m}}-t_{\mathrm{s}}\right)$, and

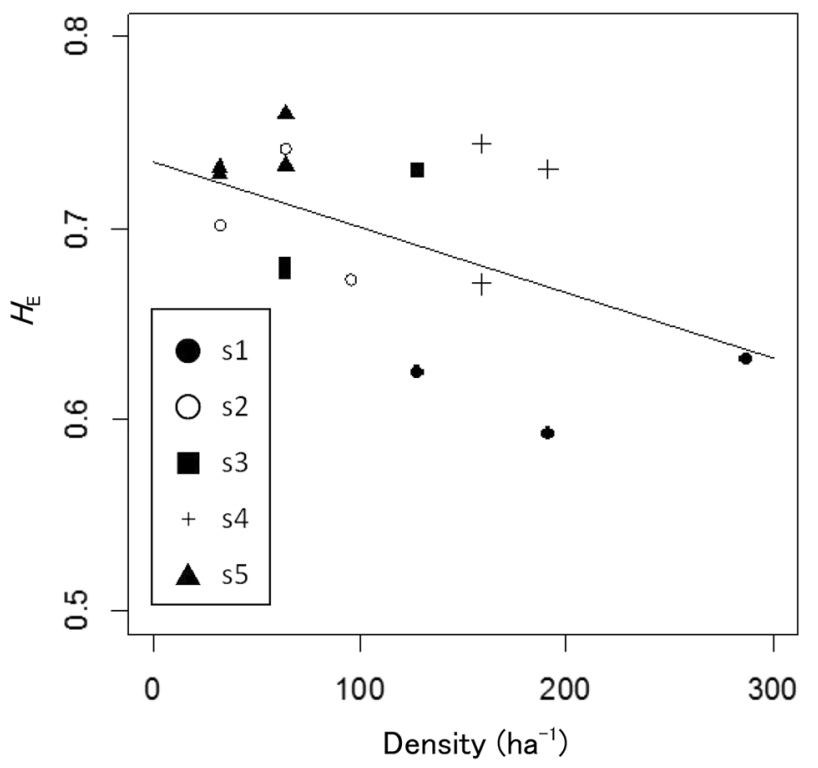

Fig. 5 Distribution of gene diversity $\left(H_{\mathrm{E}}\right)$ values of pollen pools accepted by seed parents in 2008 versus the densities of flowering individuals within 10 mradii from the respective seed parents during winter (from December 20-21, 2007 to February 22-23, 2008). Filled circles, open circles, filled squares, crosses, and filled triangles indicate the values for seed parents at the s1, s2, s3, s4, and s5 sites, respectively. Line shows a linear function fitted to the data

multilocus correlation of paternity within maternal sibships $\left(r_{\mathrm{p}}\right)$ were not high when compared with reported estimates of those for several other bird-pollinated forest tree species (Breed et al. 2015a, 2015b; Bezemer et al. 2016) and various forest tree species pollinated by animals with high mobility (Breed et al. 2015a) (Supplementary Table S2).

Our estimates for the effective numbers of pollen parents $\left(N_{\text {ep }}, 4.8-9.3\right)$ are close to previous estimates for animalpollinated forest tree species $\left[7.1 \leq\right.$ mean $N_{\text {ep }} \leq 10.6$, calculated with ten studies on the animal-pollinated species reviewed by Smouse and Sork (2004)] and is substantially lower than the estimates for wind-pollinated forest tree species [mean $N_{\text {ep }}>17.1$, calculated with 12 studies on the wind-pollinated species reviewed by Smouse and Sork (2004)]. This result is not surprising because $N_{\text {ep }}$ is inherently lower for animal-pollinated species than windpollinated species (Smouse and Sork 2004). However, the $N_{\text {ep }}$ values we found were also lower than the previous estimates for forest tree species mainly pollinated by birds [mean $N_{\text {ep }}=13.6$, calculated with 12 studies on the birdpollinated species reviewed by Krauss et al. (2017)]. Thus, we show that the overall pattern of bird pollination in this population leads to the lower diversity of pollen parents within maternal sibships than either wind-pollinated tree species or average bird-pollinated tree species, similar to that for pollination by animals other than birds. Deviation of the bird pollination from the optimal foraging behavior would induce higher diversity of pollen parents than forest 
tree species pollinated by animals other than birds (Krauss et al. 2017). However, in contrast to the other birdpollinated forest tree species, our results of low $N_{\text {ep }}$ might indicate the optimal foraging behavior of birds in the $C$. japonica population.

We found that the correlated paternity between pollen pools decreased monotonically as the distances between seed-parent pairs increased within a certain distance range (from 0 to $610.2 \mathrm{~m}$ and from 0 to $681.8 \mathrm{~m}$ in 2006 and 2008, respectively) but increased beyond this range. Different seed parents located near to each other may be frequently pollinated by the same pollen parents because of limited pollen dispersal (probably by optimal foraging behaviors of birds); therefore, correlated paternity may depend on the distance between the seed-parent pair at local scales, particularly within ca. $200 \mathrm{~m}$ (see Fig. 3). However, the increase in correlated paternity that we found with the increased distance of the seed-parent pair suggests that some processes of long-distance pollen dispersal are at work, in addition to local pollination due to the optimal foraging behavior of birds. The dispersal kernels estimated by KINDIST in our study also indicate a high potential for long-distance pollen dispersal. The shape parameters $(b)$ estimated here were similar to those in previous studies on other forest tree species that used KINDIST and assumed exponential power functions, all of which suggested longdistance mean $(\delta)$ of pollen dispersal (Lander et al. 2010; Breed et al. 2015b; Kassa et al. 2018) (Supplementary Table S3). The low shape parameters estimated here also indicate a fat-tailed dispersal distribution that may reflect the high mobility of bird pollinators.

However, the actual mean distance of pollen dispersal is likely shorter than the values (1487.4 and $1476.9 \mathrm{~m}$ in 2006 and 2008, respectively) estimated by KINDIST, which are based on the assumption of a population with an infinite area, even though the area of our study site was only $\sim 100$ ha, relatively small for estimating long pollen dispersal. Therefore, although the dispersal kernel may be valid at our scale because the dispersal kernels estimated for the two different years were very similar, the long mean distances found here may reflect an extrapolation of the observed data beyond the limited spatial scale of analysis.

Zosterops japonica (Japanese white-eye) is the main pollinator of Camellia japonica and is a territorial bird, and the agonistic interactions among the conspecific individuals of Z. japonica has been reported (Kikkawa and Kakizawa 1981). The extent of dispersal by territorial birds should depend on the magnitude of aggressive interactions (Krauss et al. 2017). The combination of agonistic interactions, high mobility, and limited grooming has been thought to promote pollen dispersal and consequently induce deviation from optimal foraging behavior (Krauss et al. 2017). Although such characteristics of $Z$. japonica might induce the long-distance pollen dispersal, the bird pollinator of $C$. japonica would also conduct optimal foraging behavior, as reflected by the dependency of the correlated paternity of pollen pool on the distance between seed-parent pair at a local scale and the low $N_{\text {ep }}$ as previously noted.

Although the seed dispersal of Camellia japonica, which is mediated by gravity and mouse, is spatially limited [mean distance for 28 of 34 seedlings estimated by maternity analysis was $5.8 \mathrm{~m} \pm 6.0 \mathrm{SD}$, Abe et al. (2006)], the finescale spatial genetic structure (FSGS) of $C$. japonica in this study site is weak (Ueno et al. 2000). Ueno et al. (2000) considered overlapping seed shadow and extensive pollen dispersal as factors that weaken the FSGS. Therefore, the long-distance pollen dispersal found here would contribute to the weakening of the FSGS of the $C$. japonica population. A strong FSGS induced by limited seed dispersal should result in a small effective number of individuals in a neighborhood $\left(N_{\mathrm{e}}\right)$, thus inducing random local genetic differentiation within a population (Crawford 1984). However, extensive pollen dispersal might mitigate the effect of restricted seed dispersal on FSGS (Grivet et al. 2009). Furthermore, bird-mediated pollen dispersal may also promote gene flow from outside the population more frequently than seed dispersal via gravity and mouse. Therefore, bird pollination may largely contribute to the maintenance of genetic diversity in $C$. japonica populations.

\section{Genetic effects of spatial variation in bird pollination on pollen pools accepted by Camellia japonica individuals}

We found that the genetic diversity of accepted pollen pools tended to be negatively related to the density of flowering individuals around seed parents during winter. Abe et al. (2011) found that the area covered by Zosterops japonica was larger and the genetic diversity of pollen attached to $Z$. japonica individuals was higher in Camellia japonica populations with lower flowering density. This characteristic of bird pollination may increase the genetic diversity of offspring in $C$. japonica populations with decreased flowering density (Abe et al. 2013). While these studies would indicate negative density-dependence of bird-pollination distance and the consequent mitigating effects over the entire population, we demonstrate in the current study the mitigating effects at local sites within a continuous population at the landscape level. The density of flowering individuals tended to be lower at higher altitude sites during winter when $C$. japonica pollination may be mediated mostly by $Z$. japonica. Furthermore, the average number of flowers per individual was lowest at the highest altitude site (s5). Therefore, low flowering density at sites such as s5 during winter may broaden the foraging area of $Z$. japonica and consequently increase the genetic diversity of pollen 
pools accepted by $C$. japonica individuals. The effect of low flowering density rather than the agnostic interaction of birds, as noted previously, could explain the long-distance pollen dispersal of $C$. japonica. Furthermore, the optimal foraging behavior of birds, as noted above, at sites with high flowering densities (i.e., effect of high flowering density) could explain the limited pollen dispersal of $C$. japonica. Thus, responses in foraging behavior to variations in local flowering density may induce spatial variations in bird pollination within the population and in the genetic diversity of pollen pools. Again, in the model, $N_{\mathrm{ep}}=8 \delta^{2} d$ (Austerlitz and Smouse 2001), where $N_{\mathrm{ep}}, \delta$, and $d$ are the effective number of pollen parents, mean distance of pollen dispersal, and density of reproductive individuals, respectively, $N_{\text {ep }}$ theoretically decrease with decreasing $d$ if $\delta$ is assumed to be constant. However, due to negative densitydependence of bird-pollination distance, $\delta$ would increase with decreasing $d$, and the effect of increasing $\delta$ on $N_{\mathrm{ep}}$ and the consequent genetic diversity of pollen pools accepted by seed parents would exceed the effects of decreasing $d$ on $N_{\text {ep. }}$. Therefore, the spatial variations in bird pollination associated with variations in flowering density may induce mitigating effects.

Similar mitigating effects of low population density have also been reported in other bird-pollinated forest tree species in fragmented forests (Breed et al. 2015a, 2015b). In this study, we detected an extreme mitigating effect not only in maintaining but also increasing the genetic diversity of pollen pools within an intact and continuous forest. Therefore, such mitigating effect of bird pollination may be innate characteristics of the bird (Z. japonica) and plant $(C$. japonica) species, and may reflect the strong interaction between the two species, in which $C$. japonica strongly depends on Zosterops japonica for pollination, and the bird strongly depends on $C$. japonica for food resources (Kunitake et al. 2004).

\section{Stability of bird pollination across different reproductive years}

The two-gener analysis based on model 2 showed the small but significant genetic differentiation of pollen pools between the two reproductive years within each seed parent. However, the analysis based on model 3 showed no genetic differentiation in the global pollen pool (averaged overall seed parents sampled across the entire population) between the two years. This may reflect small differences in combinations of mating pairs between years, although the relative contributions of each pollen parent to overall seed production in the population did not differ between years. The interannual variation of pollen pools within a seed parent in this study $\left(\Phi_{\mathrm{YF}}=0.029\right)$ was lower than windpollinated forest tree species (0.039; Nakanishi et al. 2005) and insect-pollinated forest tree species $(0.084$; Irwin et al. 2003). Therefore, the interannual differences in the patterns of bird pollination in Camellia japonica may be smaller than those for wind or insect pollination. Furthermore, patterns of correlated paternity of pollen pools and pollen dispersal kernels showed similar tendencies across the two years, and there was a significant positive correlation between years in the correlated paternity of pollen pools for each seed-parent pair. These results may indicate the stability of the pattern of bird pollination over time. In addition, the significantly positive correlation of the gene diversity values $\left(H_{\mathrm{E}}\right)$ of pollen pools accepted by each seed parent between years suggests a stable effect of bird pollination on the genetic diversity of pollen pools across years. Therefore, the overall patterns of bird pollination and their genetic effects, including the mitigation effect, may be stable over time.

\section{Conclusions}

Genetic diversity of pollen pools in Camellia japonica tended to be negatively related to the local density of flowering individuals, which may be due to the negative density-dependence of bird pollination. This dependency of bird pollination in $C$. japonica may affect the spatial variation of pollination within populations, which should affect the overall pattern of pollen dispersal, and the consequent genetic effect could contribute to the maintenance of genetic diversity within populations by increasing genetic diversity of offspring from seed parents at local sites with low flowering density. Such process may be innate characteristics of the bird (Zosterops japonica) and plant (C. japonica) species and may reflect the strong interaction between the two species. However, it may be further necessary for elucidating the overall pattern of bird pollination in more detail to examine patterns of pollen dispersal taking account of such dependency and effects of flowering density, e.g., estimation of a pollen dispersal kernel having parameters determined by the flowering density. Furthermore, because the dependence itself may be an important characteristic of bird pollination, it could be useful for characterizing the pattern of pollen dispersal for the bird-pollinated forest tree species to examine the parameters concerned with negative density-dependence of pollination, e.g., the slope for regression of genetic diversity of pollen pool on density of flowering individuals, as examined in this study.

Most of evergreen broad-leaved forests, where Camellia japonica grows, in Japan are small, at most a few hectares in size, and scattered due to strong and frequent anthropogenic disturbances for a long time (Manabe et al. 2000; Miura et al. 2001). With respect to C. japonica, the mitigating effects of bird pollination might contribute to the maintenance of genetic diversity within populations with 
decreased flowering density due to the disturbances. However, the disturbances could affect population dynamics of the bird pollinator (Zosterops japonica) by destroying habitats of the bird species, and consequently affect the mitigating effects. In order to evaluate such impacts of anthropogenic forest disturbances on the mitigating effects, future studies should examine the mitigating effects in the anthropogenically disturbed and fragmented forests and compared their results to those in the intact and continuous forest indicated by this study.

\section{Data availability}

Sampling locations, microsatellite genotypes, and flowering data are available from the Dryad Digital Repository: https://doi.org/10.5061/dryad.17q550q.

Acknowledgements We thank the Tsushima District Forest Office for allowing us to conduct this study and Dr Ikutaro Tsuyama and Prof. Peter Smouse for their technical advice. We are grateful to members of the Laboratory of Forest Ecology and Physiology of Nagoya University, who provided field and/or laboratory assistance. We also thank the anonymous reviewers for their invaluable comments.

\section{Compliance with ethical standards}

Conflict of interest The authors declare that they have no conflict of interest.

Publisher's note: Springer Nature remains neutral with regard to jurisdictional claims in published maps and institutional affiliations.

\section{References}

Abe H, Matsuki R, Ueno S, Nashimoto M, Hasegawa M (2006) Dispersal of Camellia japonica seeds by Apodemus speciosus revealed by maternity analysis of plants and behavioral observation of animal vectors. Ecol Res 21:732-740

Abe H, Ueno S, Takahashi T, Tsumura Y, Hasegawa M (2013) Resilient plant-bird interactions in a volcanic island ecosystem: pollination of japanese camellia mediated by the Japanese whiteeye. PLoS ONE 8:e62696

Abe H, Ueno S, Tsumura Y, Hasegawa M (2011) Expanded home range of pollinator birds facilitates greater pollen flow of Camellia japonica in a forest heavily damaged by volcanic activity. In: Isagi Y, Suyama Y (eds) Single pollen genotyping. Springer Japan, Osaka, p 47-62

Austerlitz F, Smouse PE (2001) Two-generation analysis of pollen flow across a landscape. II. Relation between $\Phi_{\mathrm{ft}}$, pollen dispersal and interfemale distance. Genetics 157:851-857

Bezemer N, Krauss SL, Phillips RD, Roberts DG, Hopper SD (2016) Paternity analysis reveals wide pollen dispersal and high multiple paternity in a small isolated population of the bird-pollinated Eucalyptus caesia (Myrtaceae). Heredity 117:460-471

Breed MF, Ottewell KM, Gardner MG, Marklund MHK, Dormontt EE, Lowe AJ (2015a) Mating patterns and pollinator mobility are critical traits in forest fragmentation genetics. Heredity 115:108-114

Breed MF, Ottewell KM, Gardner MG, Marklund MHK, Stead MG, Harris JBC et al. (2015b) Mating system and early viability resistance to habitat fragmentation in a bird-pollinated eucalypt. Heredity 115:100-107

Crawford TJ (1984) The estimation of neighbourhood parameters for plant populations. Heredity 52:273-283

Excoffier L, Smouse PE, Quattro JM (1992) Analysis of molecular variance inferred from metric distances among DNA haplotypes: application to human mitochondrial DNA restriction data. Genetics 131:479-491

Fang Q, Chen YZ, Huang SQ (2012) Generalist passerine pollination of a winter-flowering fruit tree in central China. Ann Bot 109:379-384

Fukue Y, Kado T, Lee SL, Ng KKS, Muhammad N, Tsumura Y (2007) Effects of flowering tree density on the mating system and gene flow in Shorea Leprosula (Dipterocarpaceae) in Peninsular Malaysia. J Plant Res 120:413-420

Grivet D, Robledo-Arnuncio JJ, Smouse PE, Sork VL (2009) Relative contribution of contemporary pollen and seed dispersal to the effective parental size of seedling population of California valley oak (Quercus lobata, Née). Mol Ecol 18:3967-3979

Hardy OJ (2009) How fat is the tail? Heredity 103:437-438

Hardy OJ, Gonzalez-Martinez SC, Colas B, Freville H, Mignot A, Olivieri I (2004) Fine-scale genetic structure and gene dispersal in Centaurea corymbosa (Asteraceae). II. Correlated paternity within and among sibships. Genetics 168:1601-1614

Irwin AJ, Hamrick JL, Godt MJW, Smouse PE (2003) A multiyear estimate of the effective pollen donor pool for Albizia julibrissin. Heredity 90:187-194

Itow S (1991) Species turnover and diversity patterns along an evergreen broad-leaved forest coenocline. J Veg Sci 2:477-484

Kassa A, Konrad H, Geburek T (2018) Mating pattern and pollen dispersal in the wild olive tree (Olea europaea subsp. cuspidata). Tree Genet Genomes 14:3

Kikkawa J, Kakizawa R (1981) Agonistic behaviour of Japanese White-eyes Zosterops japonica on Miyake Island. J Yamashina Inst Ornithol 13:60-70

Krauss SL, Phillips RD, Karron JD, Johnson SD, Roberts DG, Hopper SD (2017) Novel consequences of bird pollination for plant mating. Trends Plant Sci 22:395-410

Kunitake Y, Hasegawa M, Miyashita T, Higuchi H (2004) Role of a seasonally specialist bird Zosterops japonica on pollen transfer and reproductive success of Camellia japonica in a temperate area. Plant Species Biol 19:197-201

Lander TA, Boshier DH, Harris SA (2010) Fragmented but not isolated: contribution of single trees, small patches and long-distance pollen flow to genetic connectivity for Gomortega keule, an endangered Chilean tree. Biol Conserv 143:2583-2590

Manabe T, Nishimura N, Miura M, Yamamoto S (2000) Population structure and spatial patterns for trees in a temperate old-growth evergreen broad-leaved forest in Japan. Plant Ecol 151:181-197

Miura M, Manabe T, Nishimura N, Yamamoto S (2001) Forest canopy and community dynamics in a temperate old-growth evergreen broad-leaved forest, south-western Japan: a 7-year study of a 4-ha plot. J Ecol 89:841-849

Murray MG, Thompson WF (1980) Rapid isolation of high molecular weight plant DNA. Nucleic Acids Res 8:4321-4325

Nakanishi A, Tomaru N, Yoshimaru H, Manabe T, Yamamoto S (2005) Interannual genetic heterogeneity of pollen pools accepted by Quercus salicina individuals. Mol Ecol 14:4469-4478

Oddou-Muratorio S, Klein EK, Demesure-Musch B, Austerlitz F (2006) Real-Time patterns of pollen flow in the wild-service tree, Sorbus torminalis (Rosaceae). III. Mating patterns and the ecological maternal neighborhood. Am J Bot 93:1650-1659

Peakall R, Smouse PE (2006) GenAlEx6: genetic analysis in excel. Population genetic software for teaching and research. Mol Ecol Notes 6:288-295 
R Development Core Team (2012) R: a language and environment for statistical computing. R Foundation for Statistical Computing, Vienna

Ritland K (2002) Extensions of models for the estimation of mating systems using $n$ independent loci. Heredity 88:221-228

Robledo-Arnuncio JJ, Austerlitz F, Smouse PE (2006) A new method of estimating the pollen dispersal curve independently of effective density. Genetics 173:1033-1045

Robledo-Arnuncio JJ, Austerlitz F, Smouse PE (2007) POLDISP: a software package for indirect estimation of contemporary pollen dispersal. Mol Ecol Notes 7:763-766

Smouse PE, Dyer RJ, Westfall RD, Sork VL (2001) Two-generation analysis of pollen flow across a landscape. I. male gamete heterogeneity among females. Evolution 55:260-271

Smouse PE, Robledo-Arnuncio JJ (2005) Measuring the genetic structure of the pollen pool as the probability of paternal identity. Heredity 94:640-649

Smouse PE, Sork VL (2004) Measuring pollen flow in forest trees: an exposition of alternative approaches. Ecol Manag 197:21-38
Stacy EA, Hamrick JL, Nason JD, Hubbell SP, Foster RB, Condit R (1996) Pollen dispersal in low-density populations of three neotropical tree species. Am Nat 148:275-298

Stiles FG (1978) Ecological and evolutionary implications of bird pollination. Am Zool 18:715-727

Taniguchi F, Fukuoka H, Tanaka J (2012) Expressed sequence tags from organ-specific cDNA libraries of tea (Camellia sinensis) and polymorphisms and transferability of EST-SSRs across Camellia species. Breed Sci 62:186-195

Ueno S, Tomaru N, Yoshimaru H, Manabe T, Yamamoto S (2000) Genetic structure of Camellia japonica L. in an old-growth evergreen forest, Tsushima, Japan. Mol Ecol 9:647-656

Wendel JF, Parks CR (1984) Distorted segregation and linkage of alcohol dehydrogenase genes in Camellia japonica L. (Theaceae). Biochem Genet 22:739-748

White GM, Boshier DH, Powell W (2002) Increased pollen flow counteracts fragmentation in a tropical dry forest: an example from Swietenia humilis Zuccarini. Proc Natl Acad Sci USA 99:2038-2042 